\title{
An Evaluation of Reliability Indices of Selected Nigerian Power Distribution Systems
}

\author{
Ganiyu Adedayo Ajenikoko ${ }^{1} \quad$ Samuel Olukunle Okeniyi $^{2} \quad$ Yusuf Mukhtar $^{3} \quad$ Sodiq Akinropo $^{4}$ \\ 1.Department of Electronic and Electrical Engineering, Ladoke Akintola University of Technology, P.M.B, 4000, \\ Ogbomoso, Nigeria \\ 2.Department of Technical Education, The College of Education, Lanlate, Oyo State
}

\begin{abstract}
A system reliability index deals with the quality of overall power supply and indicates the system character during disturbance. The performance of these indices revealed system interruption in terms of the individual customer or organization that's purchases electric energy at one location under schedule. However, maintaining these reliability indices for electricity operator is very important. Thus, measurement of system reliability indices gives response to operation personnel on reliability effects of operating and maintenance practices. This study therefore, employed the Systems Average Interruptions Duration Index (SAIDI), Systems Average Interruptions Frequency Index (SAIFI) and Customer Average Interruptions Duration Index (CAIDI) for assessment of reliability indices of selected Nigerian power distribution network. Power outage data of Ten (10) were obtained from Ibadan, Ikeja and Port-Harcourt distribution network and analyzed using curve fitting tools in MATLAB. The reliability indices were computed and their means and standard deviations were calculated. The results showed that the reliability indices were effective for reliability assessment of electrical distribution network.
\end{abstract} Keywords: Reliability Indices, SAIDI, SAIFI, CAIDI, Distribution Network, Means and Standard Deviations.

DOI: $10.7176 / \mathrm{CEIS} / 12-3-03$

Publication date: November $30^{\text {th }} 2021$

\section{I.Introduction}

The ability of power system to provide adequate electricity supply with satisfactory quality is refers to System reliability. This reliability is made up of both adequacy and security assessment [1]. The formal deals with static condition and does not include the evaluation of the system response to transient disturbances. While the latter deals with the ability of the power system to survive sudden disturbances [13], [18].

In order to avoid excessive shortages in maintaining the desired level of adequacy in power system, additional energy reserve must be conserved [2]. The adequacy of the system deals with the existence generation, transmission and distribution facilities to satisfy customer energy demand. These related with the steady state conditions and system planning for long and short terms [9].

Reliability assessment of power distribution deals with adequacy of overall system supply and indicates the system behaviour and response at the customer end. Customer can be an organization or individual that's purchases electric energy at one location. Thus, the performance indices express interruption in terms of the customers. However, the average duration of interruptions that customers experience is high but varies from place to place [8], [12], [14], [20].

In addition, the reliability of any power system can be arbitrated on the basis of system reliability indices. The Institute of Electrical and Electronic Engineers (IEEE) defines the reliability indices for distribution system in its standard number P1366, "Guide for Electrical Distribution Reliability Indices" as System Average Interruption Duration Index (SAIDI), System Average Interruption Frequency Index (SAIFI) and Customer Average Interruption Duration Index (CAIDI) [1-2].

\section{A.System Average Interruption Frequency Index}

System Average Interruption Frequency Index (SAIFI) analyses the average frequency of sustained interruptions per customer over a specified area [22]. The number of customers and the interruptions experienced are varying from time to time. For instance, SAIFI indicates the average number of interruptions a customer experience on a particular feeder. Similarly it's reported that a substation encloses the total customers in the service area [25]. The equation for SAIFI is given by [8].

$$
\text { SAIFI }=\frac{\text { TotalNumberofCustomersinterruptions }}{\text { TotalNumberofCustomersServed }}
$$

Data of individual sustained interruptions in a year are required to calculate this index. The number of customers affected for each of the interruptions, comprises the customer interruptions for the particular outage. Thus, the SAIFI is represented by [8]:

Where:

$$
S A I F I=\frac{\sum N_{i}}{N_{T}}
$$


$\mathrm{N}_{\mathrm{i}}$ is the number of interrupted customers for each interruption and $\mathrm{N}_{\mathrm{T}}$ is the total number of customers served in the area.

\section{B.System Average Interruption Duration Index}

An average time for a customer to experience an interruption during a time cycle is known as System Average Interruption Duration Index (SAIDI). The index is calculated by dividing the sum of all customer interruption durations during a year by the number of customers served and is given by [23-24].

$$
S A I D I=\frac{\sum \text { CustomerInterruptionDurations }}{\text { TotalNumberofCustomersServed }}
$$

This index can be improved by reducing the duration of the interruptions. For a given service area, SAIDI is represented as [23-24]:

$$
S A I D I=\frac{\sum r_{i} N_{i}}{N_{T}}
$$

\section{C.Customer Average Interruption Duration Index}

An average interruption duration experience by customer during a year is called Customer Average Interruption Duration Index (CAIDI). The index is the ratio of SAIDI to SAIFI as given in equations (2) and (4) respectively and is given as [15] [21]:

$$
\text { CAIDI }=\frac{\sum \text { CustomerInterruptionDurations }}{\text { TotalNumberofCustomerInterruption }}
$$

The value of CAIDI for a given service area is given as:

$$
C A I D I=\frac{\sum r_{i} N_{i}}{\sum N_{i}}
$$

\section{II.Distribution Network}

Electrical distribution network is the last stage in transmitting of electric power, whose main function is to provide power to individual consumer premises. This network is the most visible part of the supply chain and the most observed by the utilities for investment, maintenance and operation. Distribution of electrical power to different consumers is done with much low voltage level relatively to that of transmission [13]. Distribution networks are built as interconnected networks concerned with the conveyance of power to consumers by means of lower voltage network. Design of distribution network is such that normal operation is reasonably close to balance three-phase system [5], [9], [19].

The distribution network comprises of primary and secondary feeders. The formal lower the transmission voltage to medium voltage and transmit the electrical energy from substation to service transformers while the latter transfers the electrical power to the various houses through the secondary conductors [11]. In addition distribution network consists of the secondary mains, primary mains, distribution centers and the feeders as [3-4] [6], [8], [10-11], [17]:

i. Secondary Mains: Secondary mains are conductors which originate from the secondary winding of the distribution transformers and are extended along the streets. The secondary mains in residential area may be two wires, three wires or four wires system. The common secondary voltage used in Nigeria is single phase or $415 \mathrm{~V}, 3$ - phase system.

ii. Primary Mains: These are circuits which originate from the distribution centres. They are usually connected to the main distribution feeders. The primary mains are operated at the same voltage as the main distribution feeder circuit. In industrial areas, the primary mains are often connected into what is known as the primary ring. In primary main loop, a number of sectionalizing switches are inserted in the loop at the distribution transformer locations. In such a loop, power can flow around the loop in either one or two directions. However, if there is a fault in the system, the sectionalizing switches on one side of the loop is opened and service is maintained on the other side of the loop.

iii. Distribution Centres: These are locations at which the feeders are connected to the primary main switches. The switches and the automatic cut-out from control and protection of the primary mains are grouped at the distribution centres. The voltage at the distribution centres should be maintained practically constant from no load to full load. This is always accomplished by means of voltage feeder regulators at the substation.

iv. Feeders: These are conductors in a distribution system which extends the substation to the various distribution centres. The connection of the feeder could be overhead or underground.

In addition, distribution networks are classified as ring type and the radial type [7]. The ring type distribution network operate on the principle of circular distribution in which any substation is fed from two different directions. A fault on the system can be disconnected without loss of power supply to other consumers without faults. The feeders used on ring distribution depend on the nature of loading, the total length of the ring 
distributor, and the allowable voltage drops. For maintaining continuity of service, ring distribution system is usually employed [16]. The radial type of distribution network operates such that the substation transformers are fed only in one direction. One major disadvantage of this system of distribution is that the consumers have to depend on one feeder only. So if there is any fault or breakdown occurs on the feeder, the supply of power is completely taken off until the fault is rectified and the line is restored [19].

\section{III.Materials and Method}

This research work analyzed the assessment of system reliability indices of selected Nigerian power distribution network which are Ibadan, Ikeja and Port-Harcourt distribution network. Ten years of outage data were collected from the records of the network operators and analyzed. A Pseudo code was written using MATLAB program for electrical distribution network reliability analysis using curve fitting tools. The three major reliability indices (SAIDI, SAIFI and CAIDI) for the selected power distribution network in the study area were identified, computed and their mean and standard deviations were calculated.

\section{BEGIN}

The Pseudo code for calculation of SAIDI is given as;

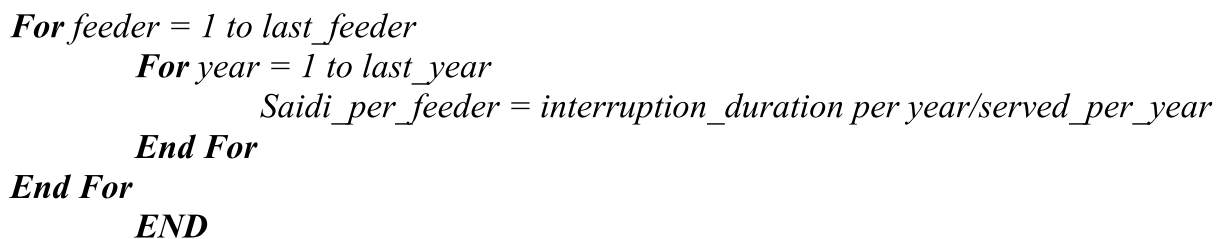

Hence, the SAIDI were computed as;

$$
\begin{gathered}
\text { SAIDI }=\frac{\sum \text { CustomerInterruptionDurations }}{\text { TotalNumberofCustomersServed }} \\
=\frac{\sum r_{i} N_{i}}{N_{T}}
\end{gathered}
$$

Also, the Pseudo code for calculation of SAIFI is given as;

\section{BEGIN}

For feeder $=1$ to last feeder

For year $=1$ to last year

\section{End For}

Saifi_per_feeder $=$ interruption_per_year/served_per_year

\section{End For}

\section{END}

Hence, the SAIFI were computed as;

$$
\begin{aligned}
\text { SAIFI }= & \frac{\text { TotalNumberofCustomersinterruptions }}{\text { TotalNumberofCustomersServed }} \\
= & \frac{\sum N_{i}}{N_{T}}
\end{aligned}
$$

Also, the Pseudo code for calculation of CAIDI is given as;

BEGIN

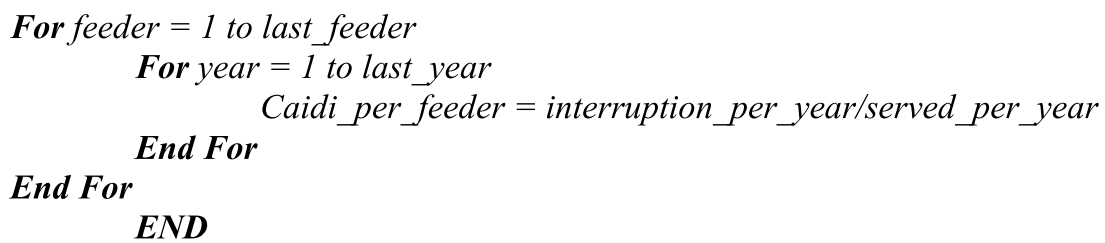

Hence, the CAIDI were computed as;

$$
\begin{gathered}
\text { CAIDI }=\frac{\sum \text { CustomerInterruptionDurations }}{\text { TotalNumberofCustomerInterruption }} \\
C A I D I=\frac{\sum r_{i} N_{i}}{\sum N_{i}}
\end{gathered}
$$

\section{Results and Discussion.}

The results of the system reliability indices for Ibadan, Ikeja and Port-Harcourt distribution network are presented. These results are discussed subsequently.

\section{A. Ibadan Distribution Network}

The highest value of mean SAIDI was recorded at Ijokodo feeder with mean SAIDI of 0.2123 and standard 
deviation of 0.0568 as shown in Figures 1 and 2. This is due to the fact that customers on this feeder were interrupted for long time while less number of customers was served. A least mean SAIDI value of 0.1446 was recorded on Agodi feeder. Also, Cocoa feeder had the highest mean SAIFI of 0.3383 with a standard deviation of 0.1325 from the mean. More customers were interrupted on this feeder. Agodi feeder had the least mean SAIFI of 0.1667 with a standard deviation of 0.1339 from the mean as illustrated in Figures 3 and 4 . This is because few customers were interrupted, thus many customers were satisfactory served by the feeder.

Moniya feeder had highest mean CAIDI of 0.8147 and a standard deviation of 0.4255 from the mean. Customers on this feeder were interrupted for a long time. Eruwa had the least mean CAIDI of 0.5955 with a standard deviation of 0.4379 as shown in Figures 5 and 6.

Figure 7 shows the combined reliability indices of Ibadan distribution network. Moniya feeder had the highest CAIDI index with a relatively low SAIDI index owing to the prolonged customers interruption on this feeder. Agodi feeder had low system reliability indices compared to all other feeders. This is as a result of customer interruptions which had reduced appreciably.

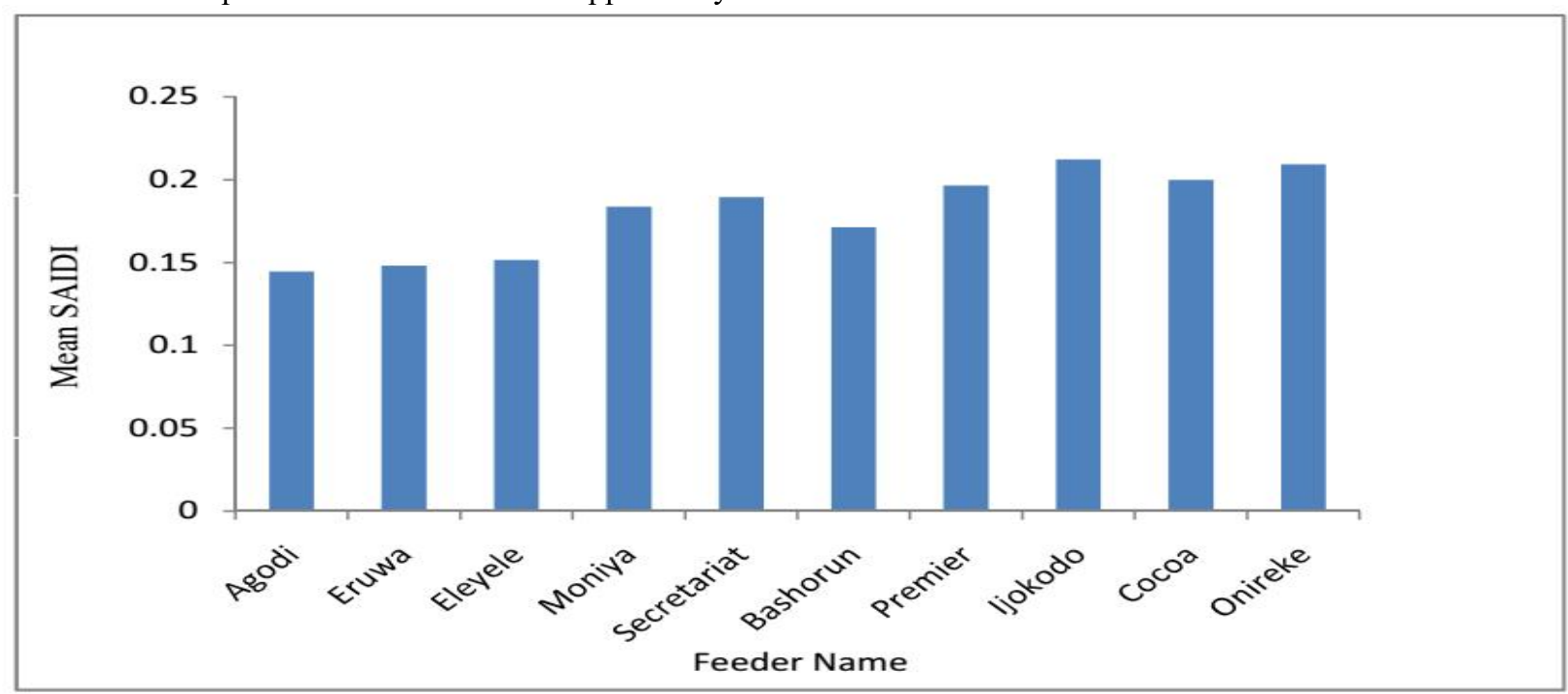

Figure 1: Mean SAIDI for Ibadan Distribution Network.

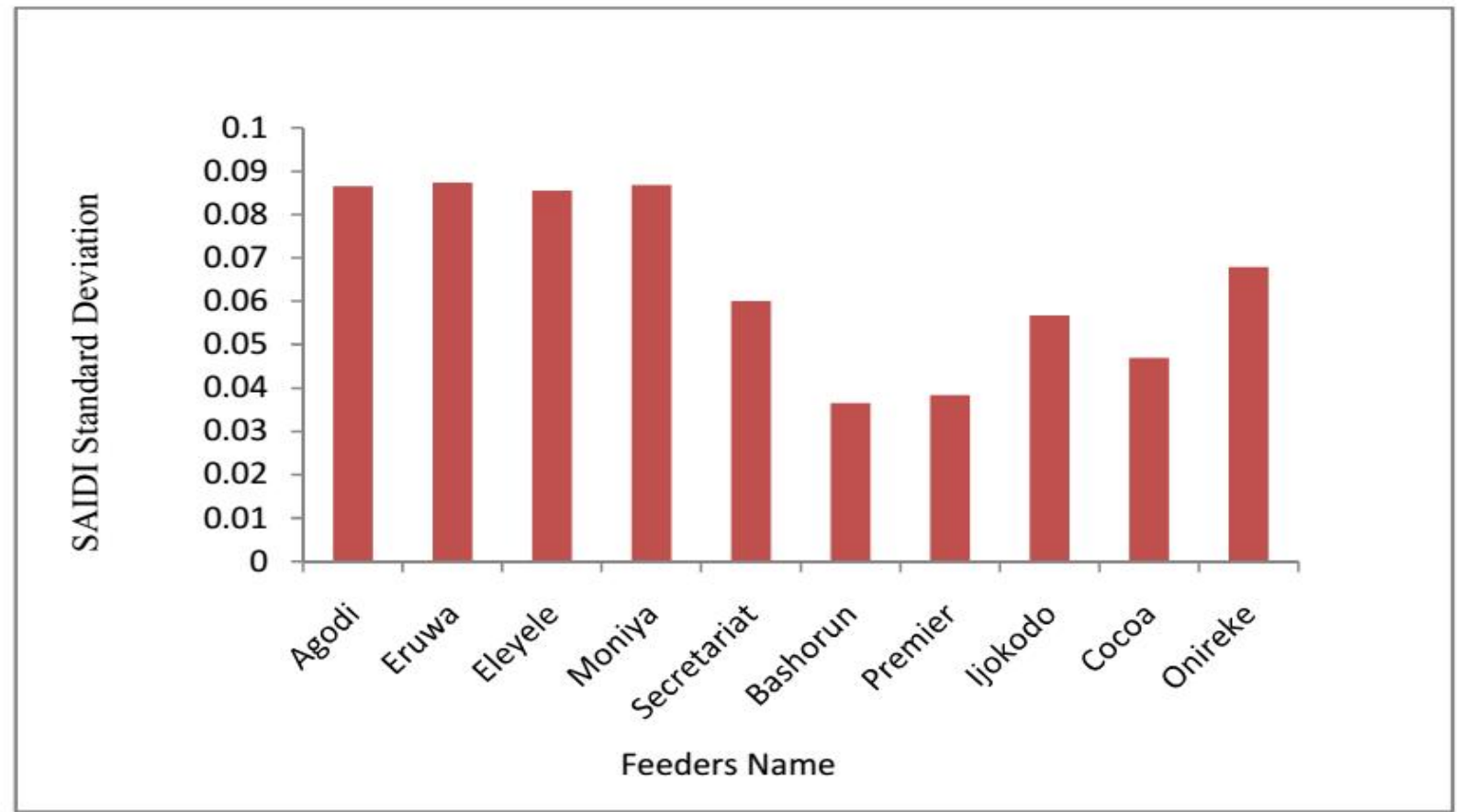

Figure 2: SAIDI Standard Deviation for Ibadan Distribution Network. 


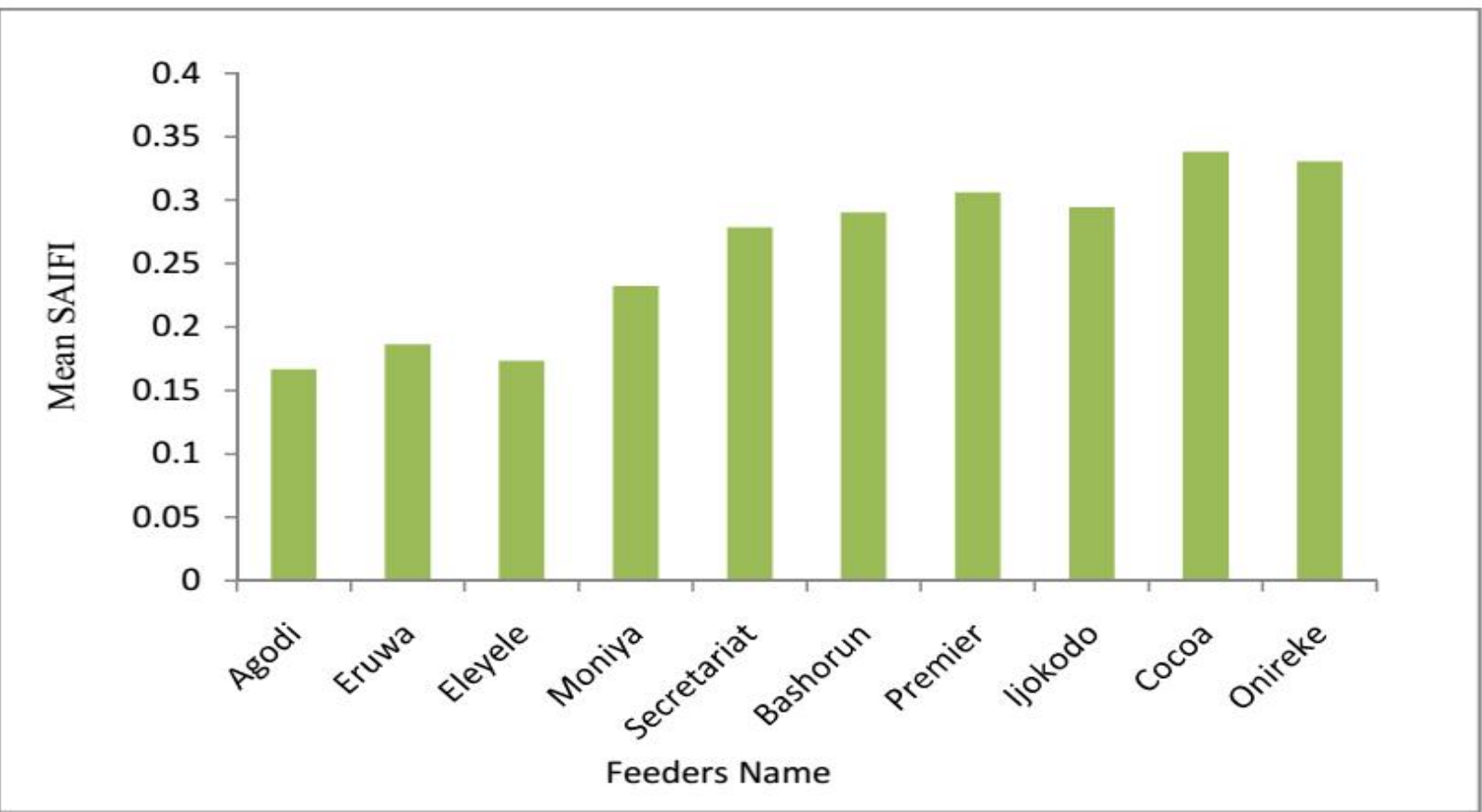

Figure 3: Mean SAIFI for Ibadan Distribution Network.

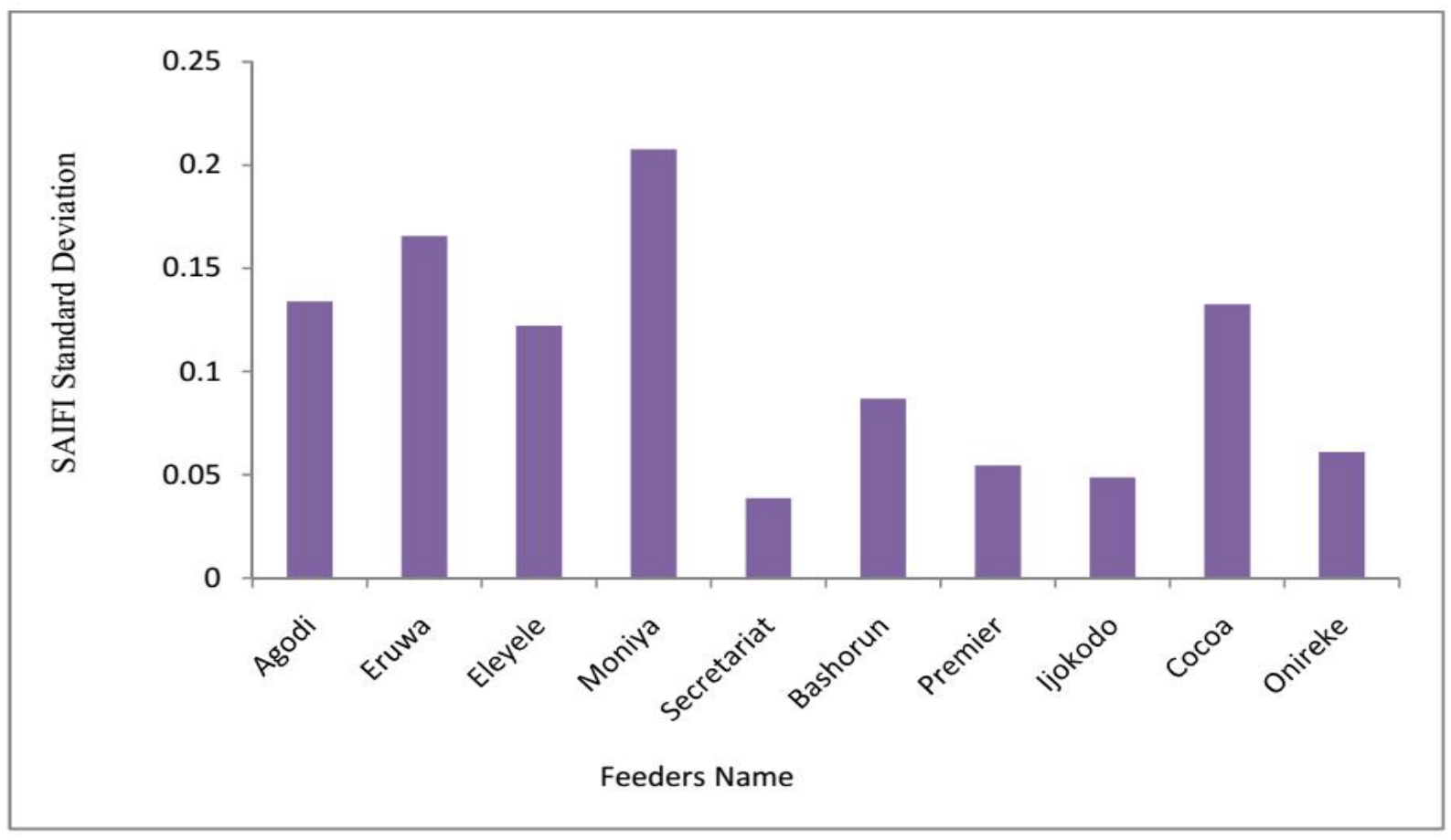

Figure 4: SAIFI Standard Deviation for Ibadan Distribution Network. 


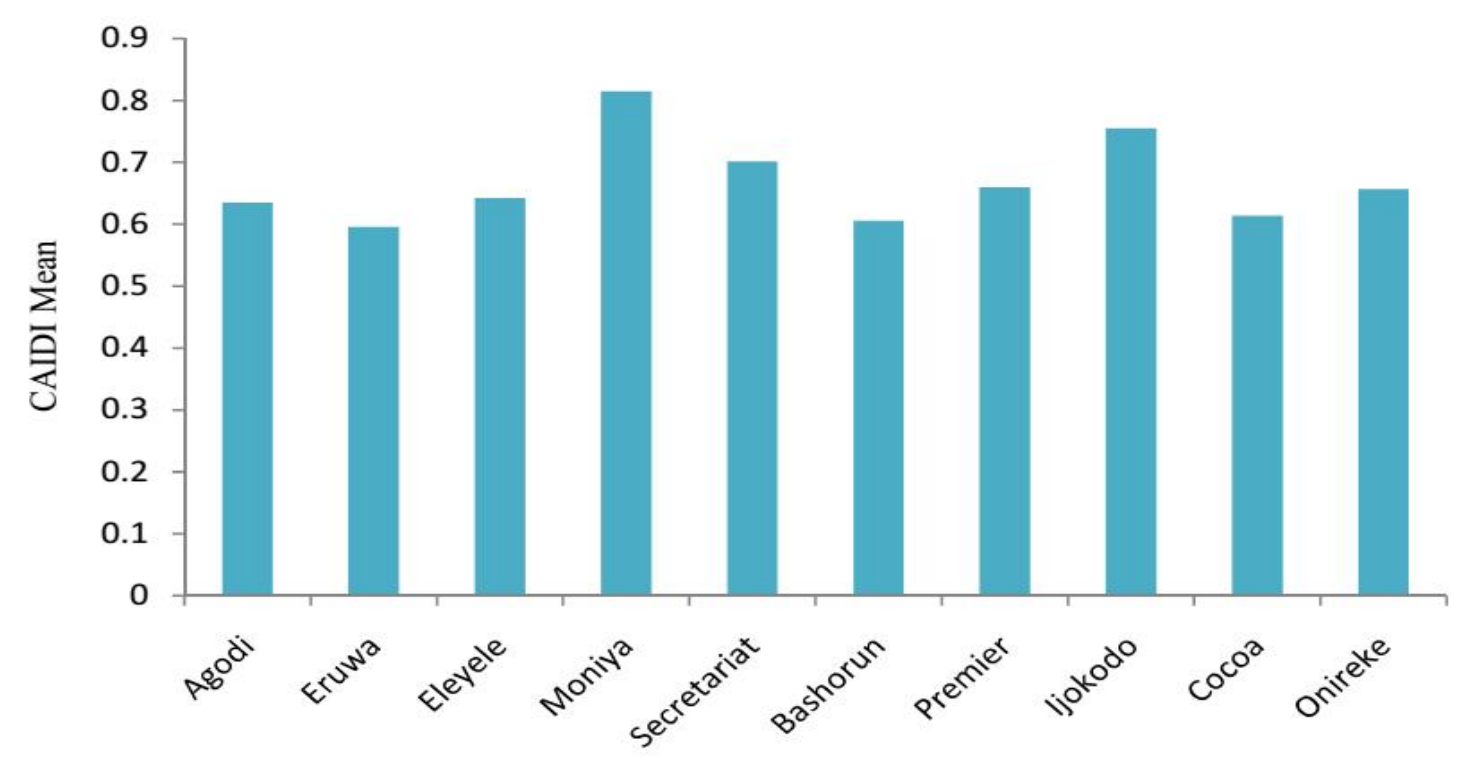

Feeders Name

Figure 5: Mean CAIDI for Ibadan Distribution Network.

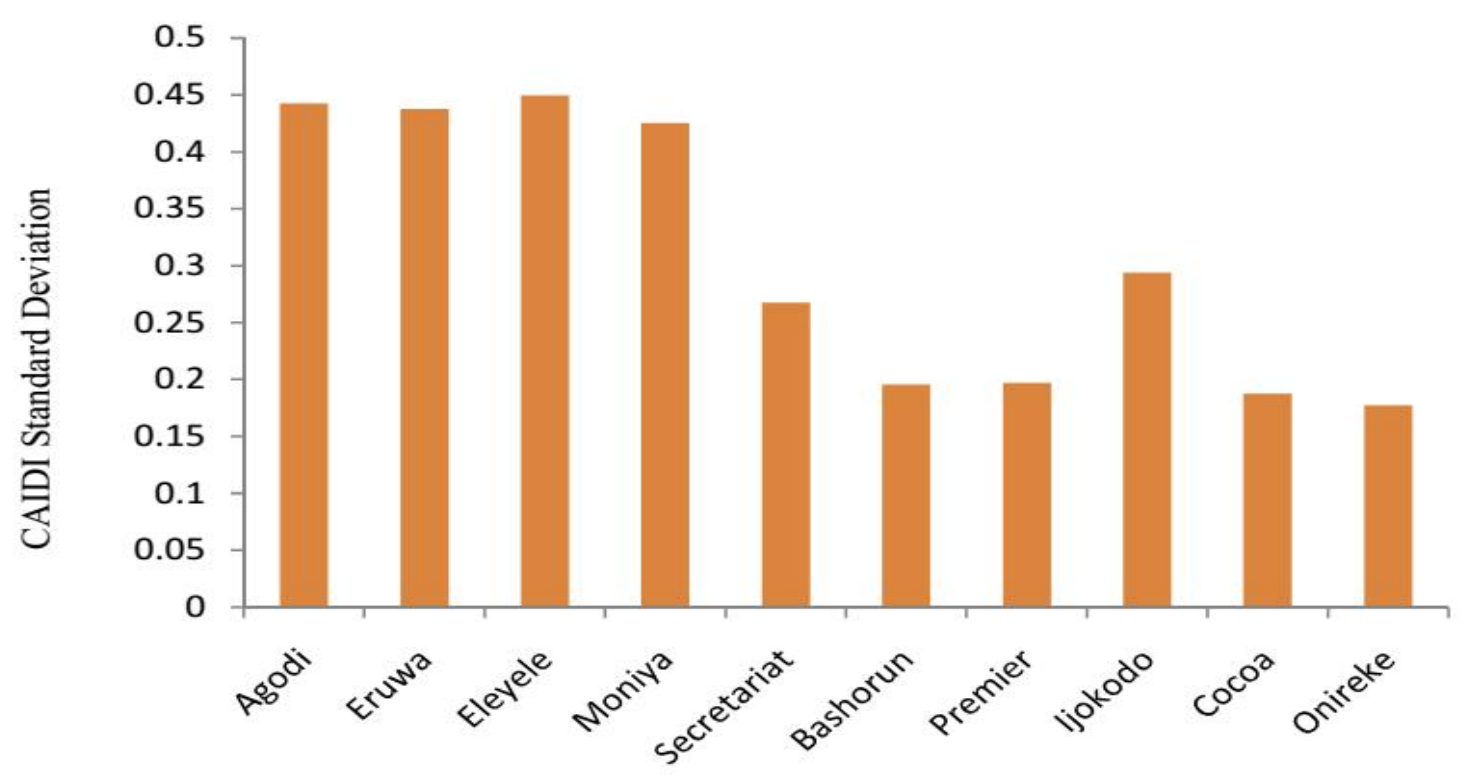

Feeders Name

Figure 6: CAIDI Standard Deviation for Ibadan Distribution Network. 


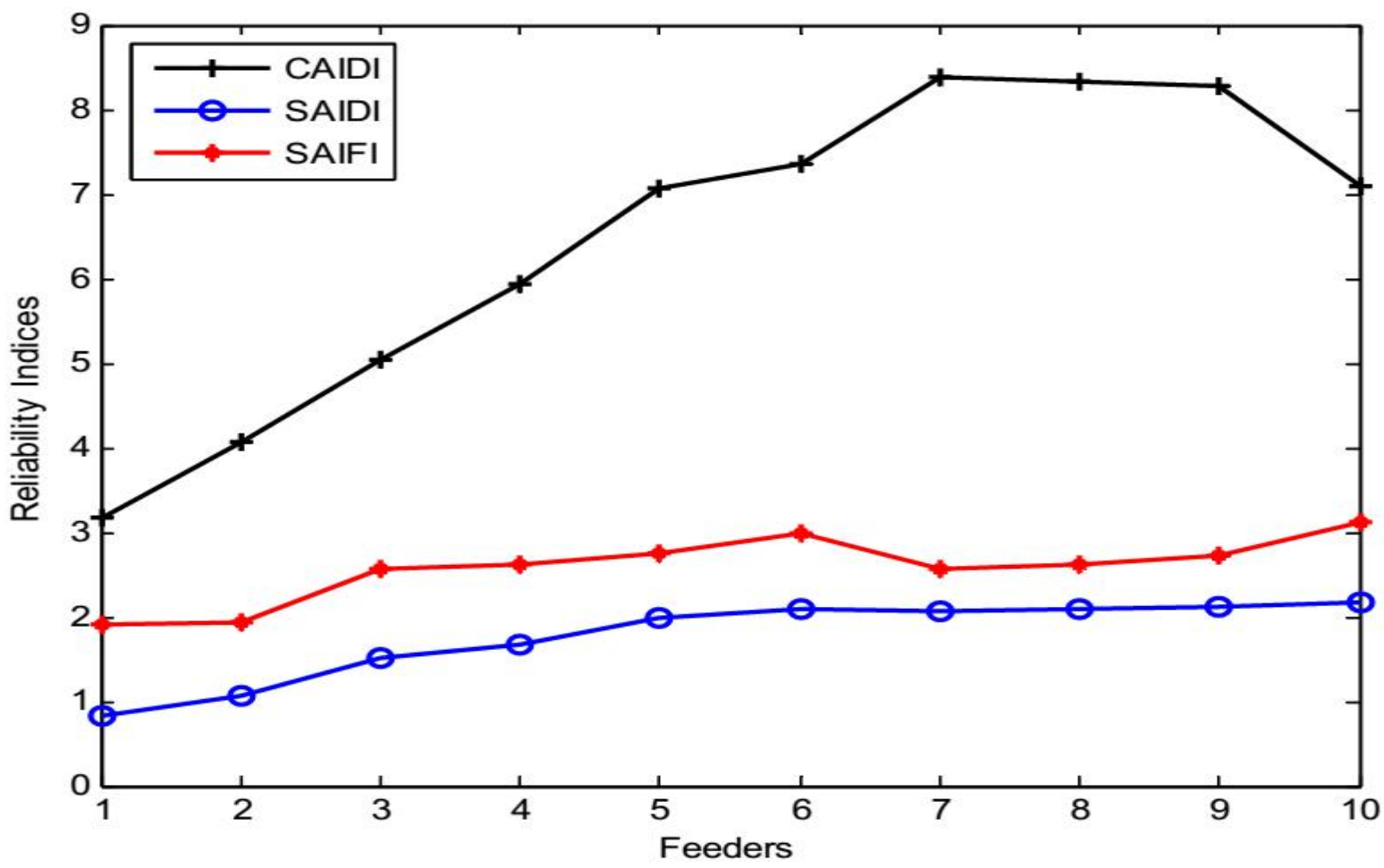

Figure 7: Combined Reliability Indices for Ibadan Distribution Network.

\section{B.Ikeja Distribution Network}

Olowu feeder had highest mean SAIDI value of 0.1040 and standard deviation value of 0.0496 as shown in Figures 8 and 9. The result showed that, the feeder handled a long period of customers' interruption. Also, 7-Up feeder had least mean SAIDI value of 0.0693 and a standard deviation of 0.0371 from the mean.

Alagbole feeder recorded highest mean SAIFI value of 0.2481 and a standard deviation value of 0.0279 as shown in Figures 10 and 11. Whereas, Opebi feeder had least mean SAIFI value of 0.1887 and a standard deviation value of 0.0168 . The least mean CAIDI of 0.2825 and a standard deviation of 0.1891 were obtained on Alagbole feeder as shown in Figures 12 and 13.

Figure 14 shows the combined reliability indices for Ikeja distribution systems. The relatively high values of CAIDI index on Olowu and Opebi distribution feeders suggested that customers on these two feeders were interrupted for a long period of time. General Hospital feeder had a low system reliability index since customers' interruption on this feeder had reduced. 


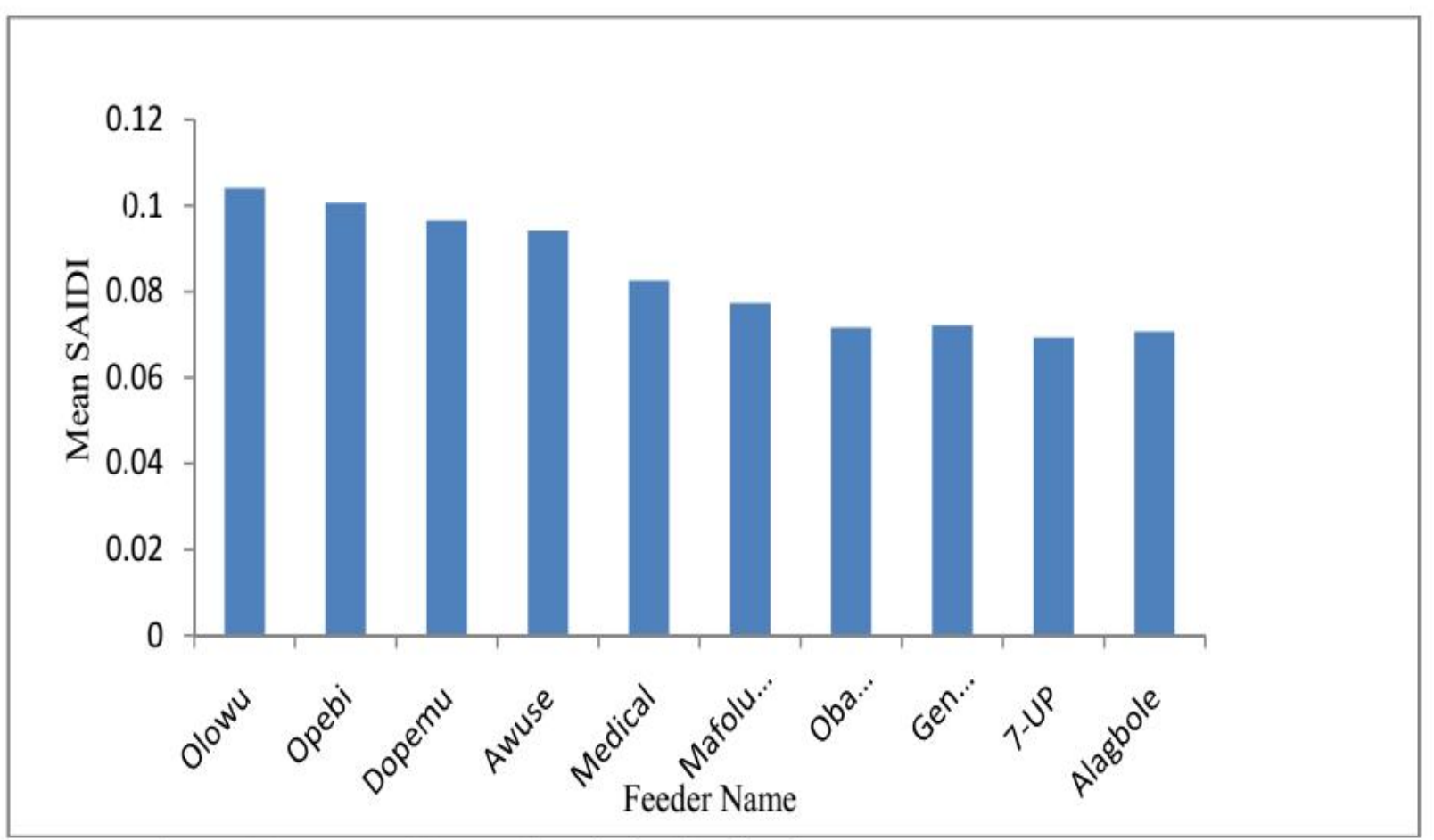

Figure 8: Mean SAIDI for Ikeja Distribution Network.

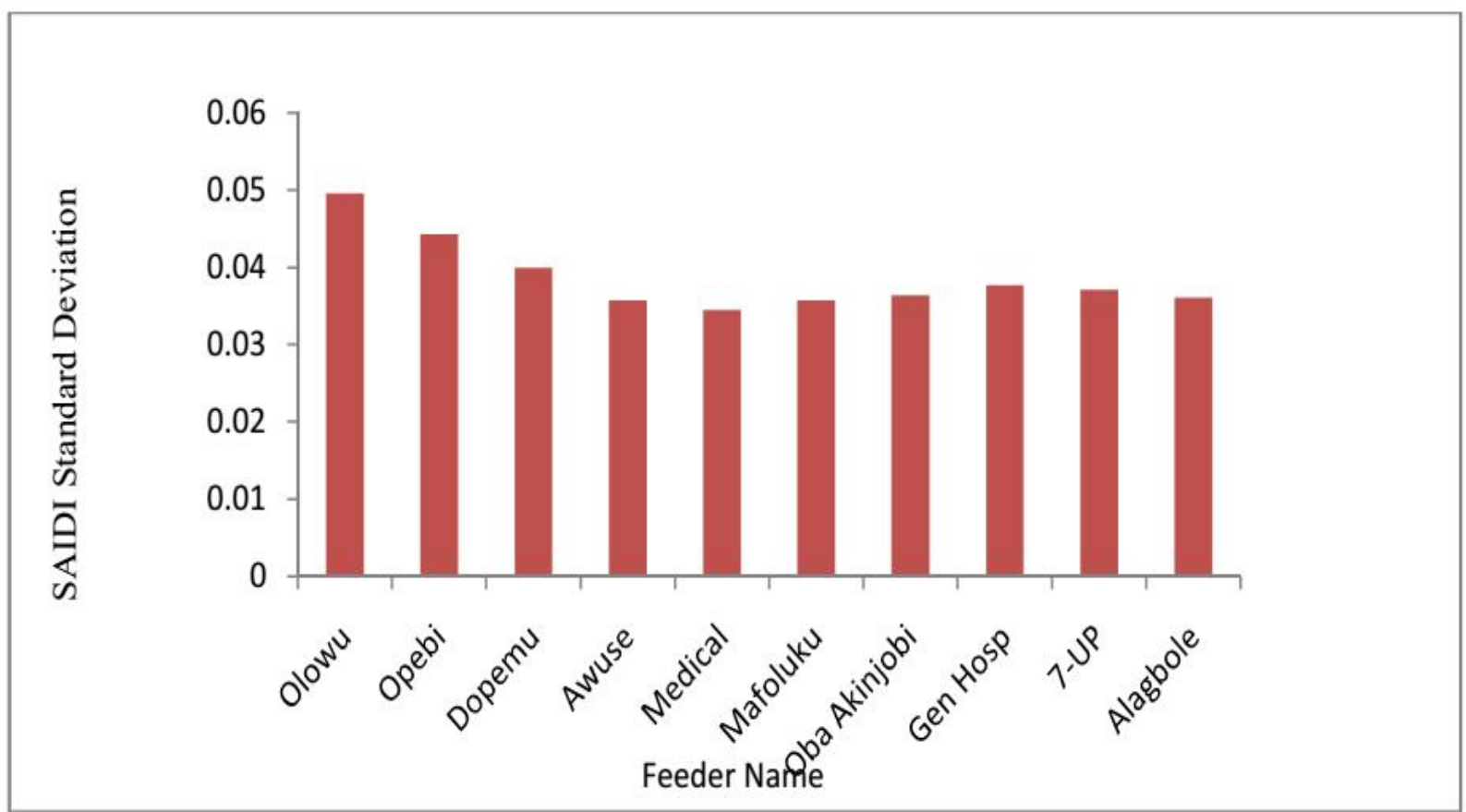

Figure 9: Standard Deviation of SAIDI for Ikeja Distribution Network. 


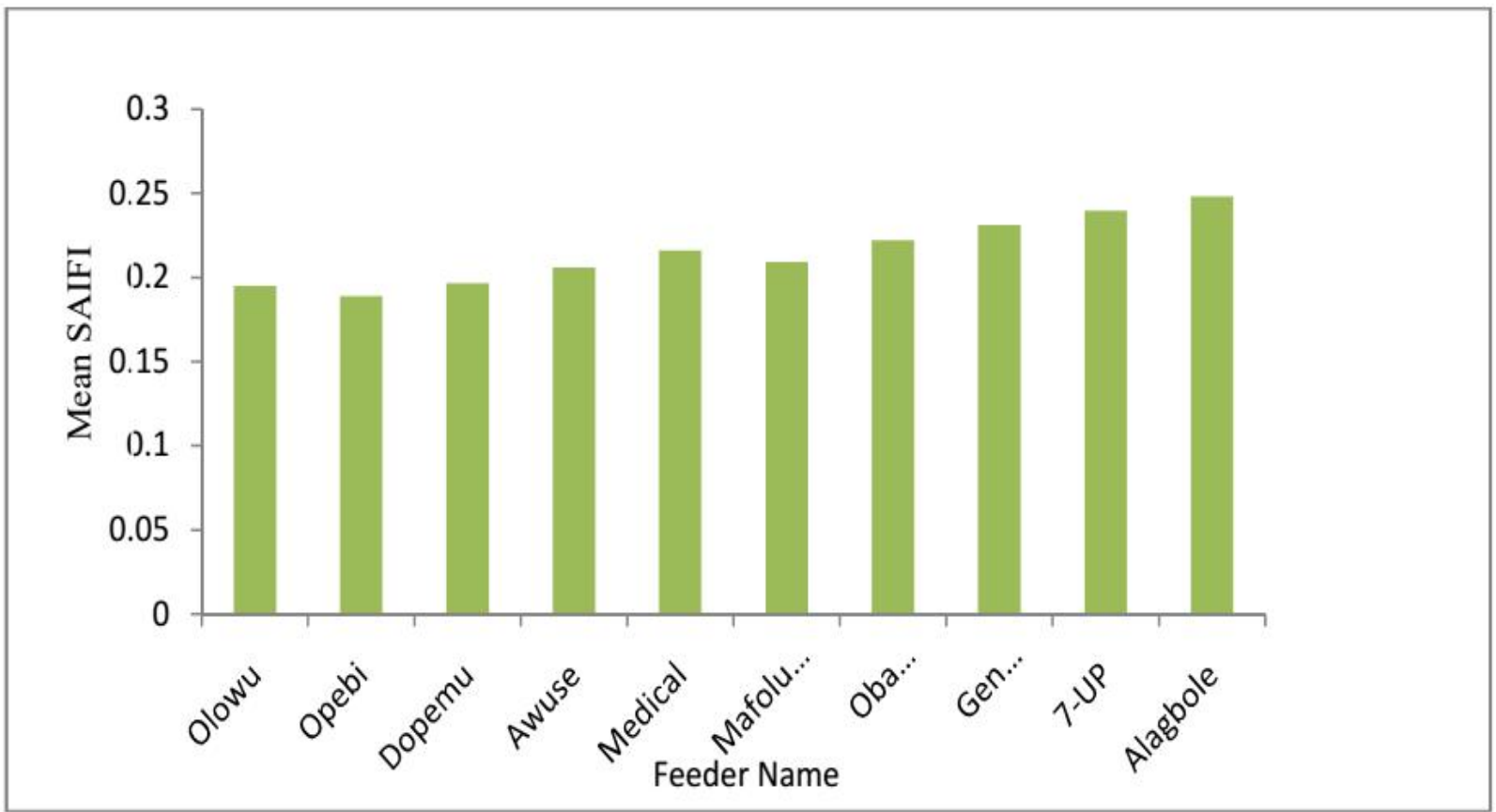

Figure 10: Mean SAIFI for Ikeja Distribution Network.

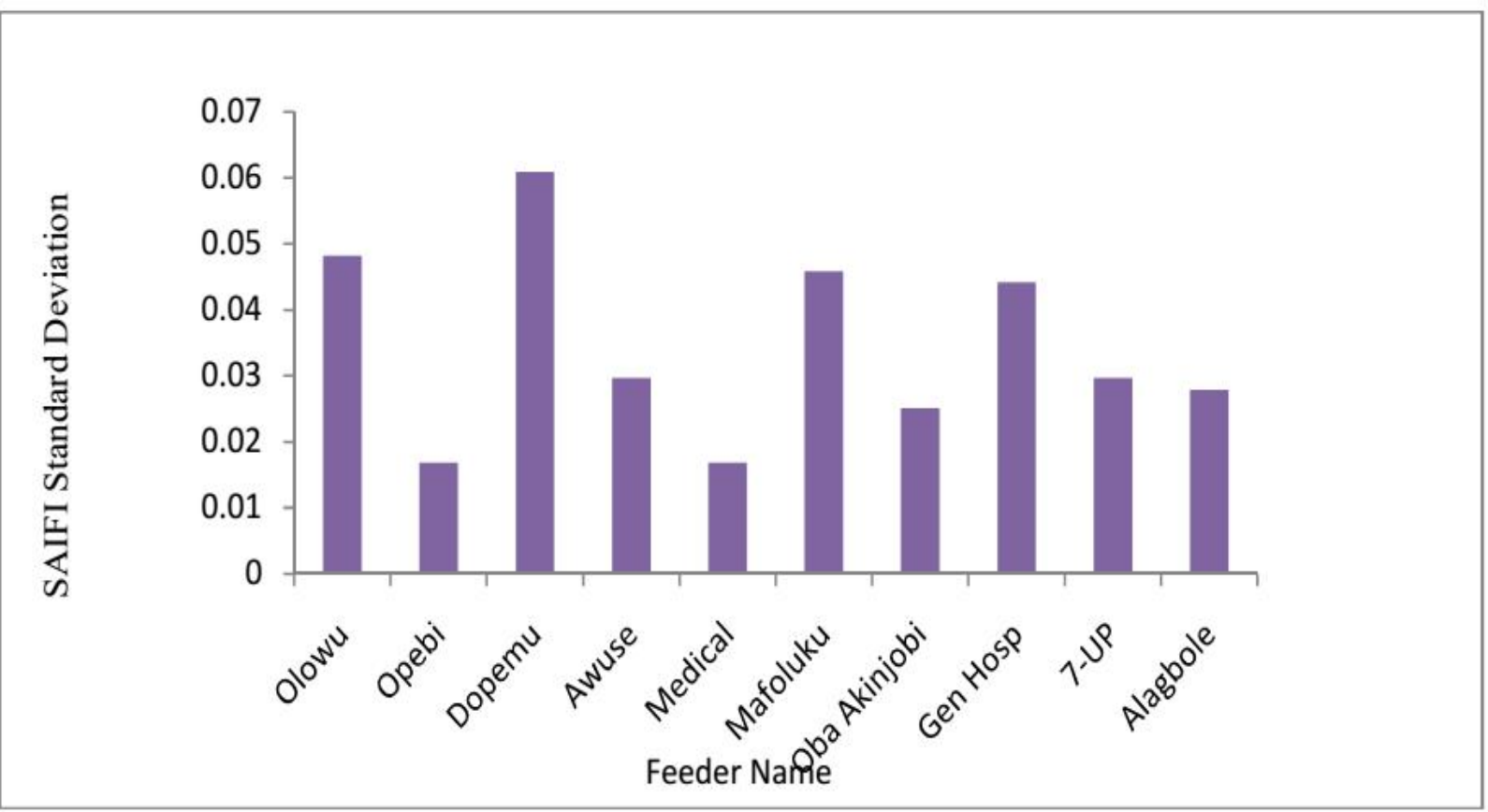

Figure 11: Standard Deviation of SAIFI for Ikeja Distribution Network. 


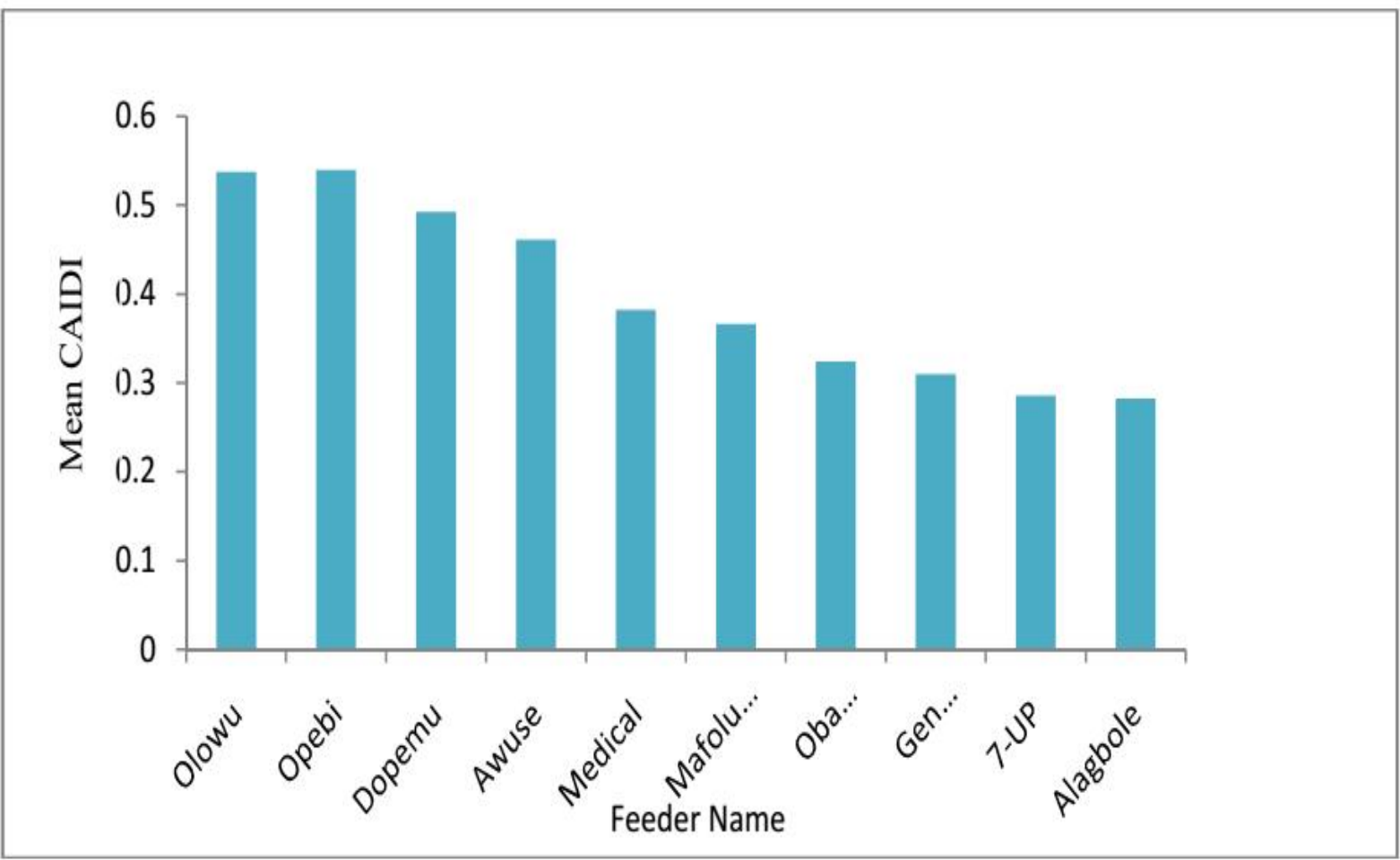

Figure 12: Mean CAIDI for Ikeja Distribution Network.

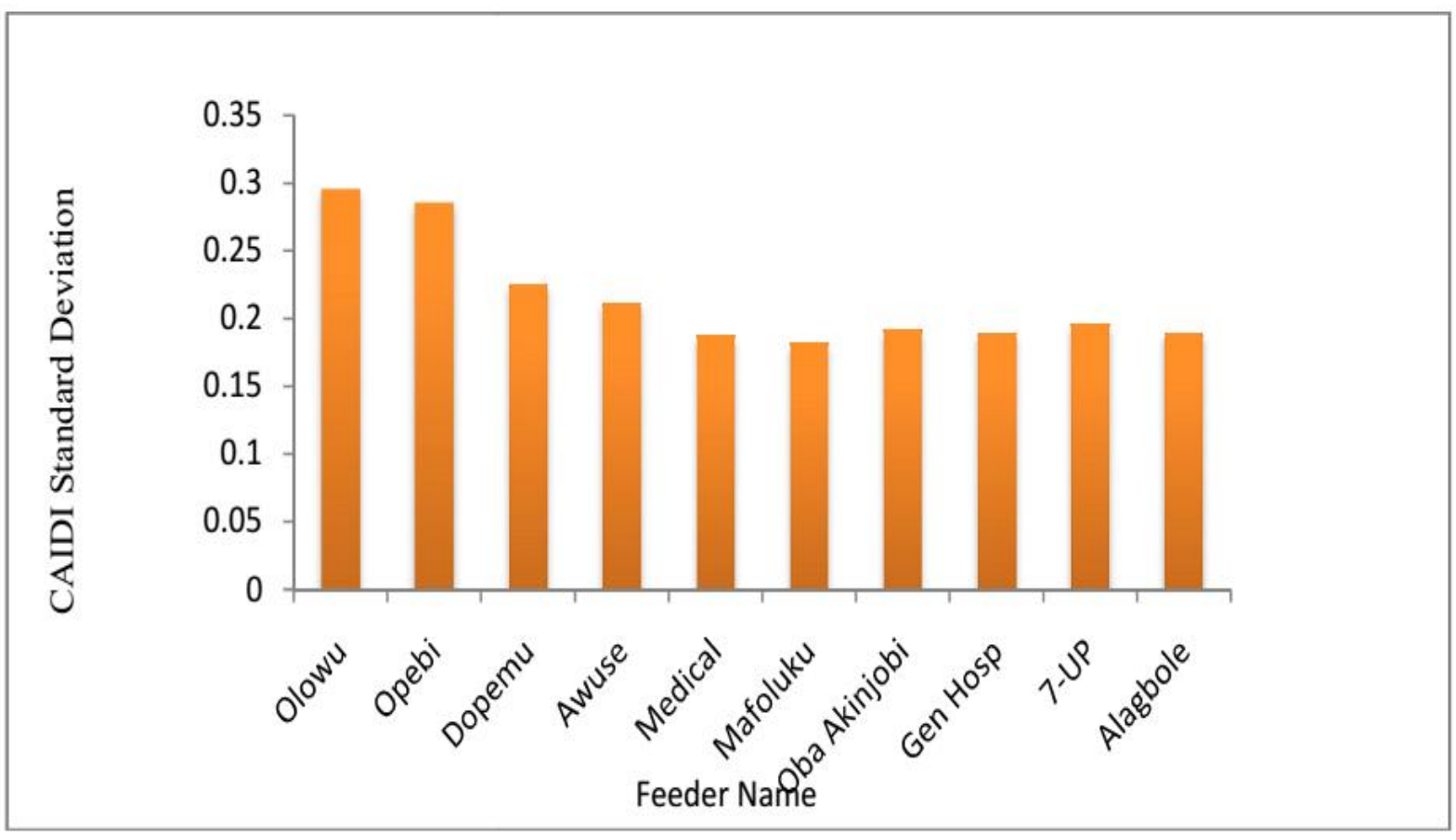

Figure 13: Standard Deviation of CAIDI for Ikeja Distribution Network. 


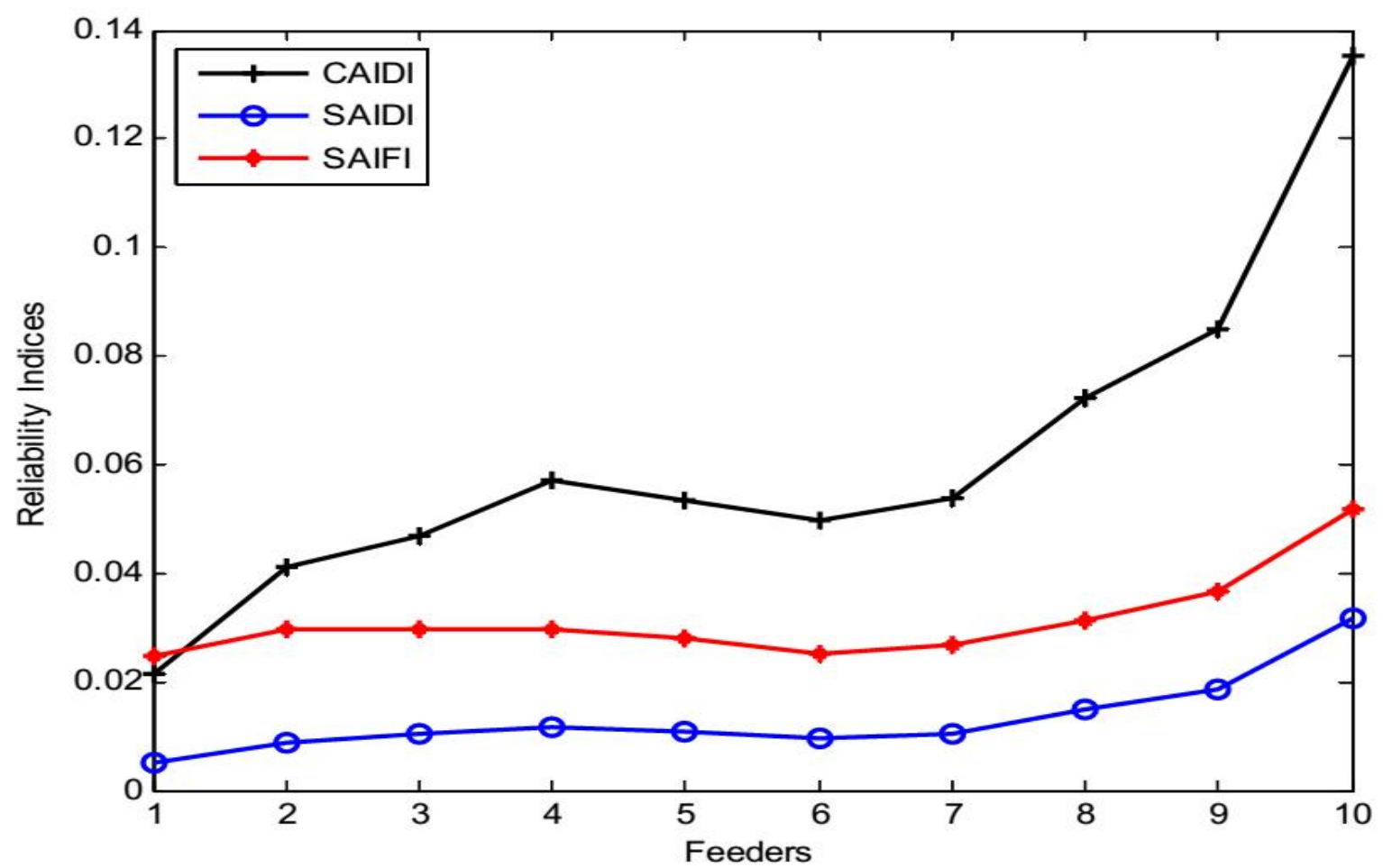

Figure 14: Combined reliability indices for Ikeja Distribution Network.

\section{C.Port-Harcourt Distribution Network}

Airport feeder of the network has highest mean SAIDI value of 0.1050 and a standard deviation of 0.0471 as shown in Figures 15 and 16. This is because customers on this feeder were not sufficiently served owing to the prolonged time of interruption. Michelin feeder had the least mean SAIDI of 0.0695 and a standard deviation of 0.0342. A shorter period of interruptions occurs in this feeder. Also, Shell 3 feeder had highest mean SAIFI of 0.1931 and a standard deviation of 0.0686 . The result showed that little customer was sufficiently served.

Airport feeder recorded least mean SAIFI value of 0.1392 and a standard deviation of 0.0198 as shown in Figures 17 and 18. Many of the customers in this feeder were served sufficiently. The feeder also has highest mean CAIDI value of 0.7651 and a standard deviation of 0.3989 as shown in Figures 19 and 20.

Michelin feeder had least mean CAIDI value of 0.3813 and standard deviation value of 0.2636 . This is due to the fact that, fewer customers in this feeder were interrupted for a short period. The reliability indices for PortHarcourt distribution network is shown in Figure 21. Customers attached to Airport and Port-Harcourt 1 feeders were interrupted for a long time, thus, making CAIDI index values of these feeders to be relatively higher than any other feeder in the distribution network. Airport and Port-Harcourt 1 feeders still maintained relatively higher values of CAIDI owing to the fact that the prolonged customers' interruptions on these two feeders still continued. 


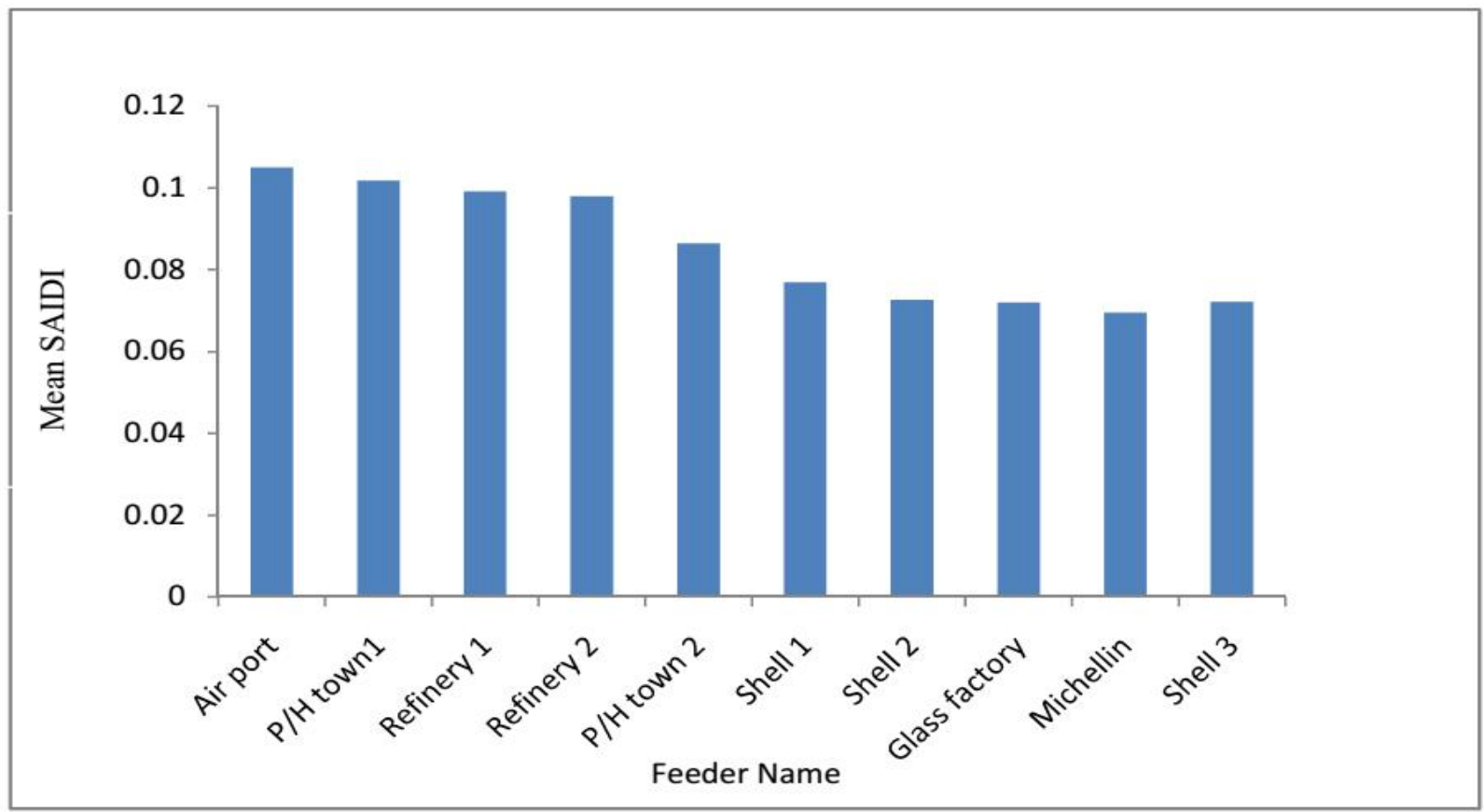

Figure 15: Mean SAIDI for Port-Harcourt Distribution Network.

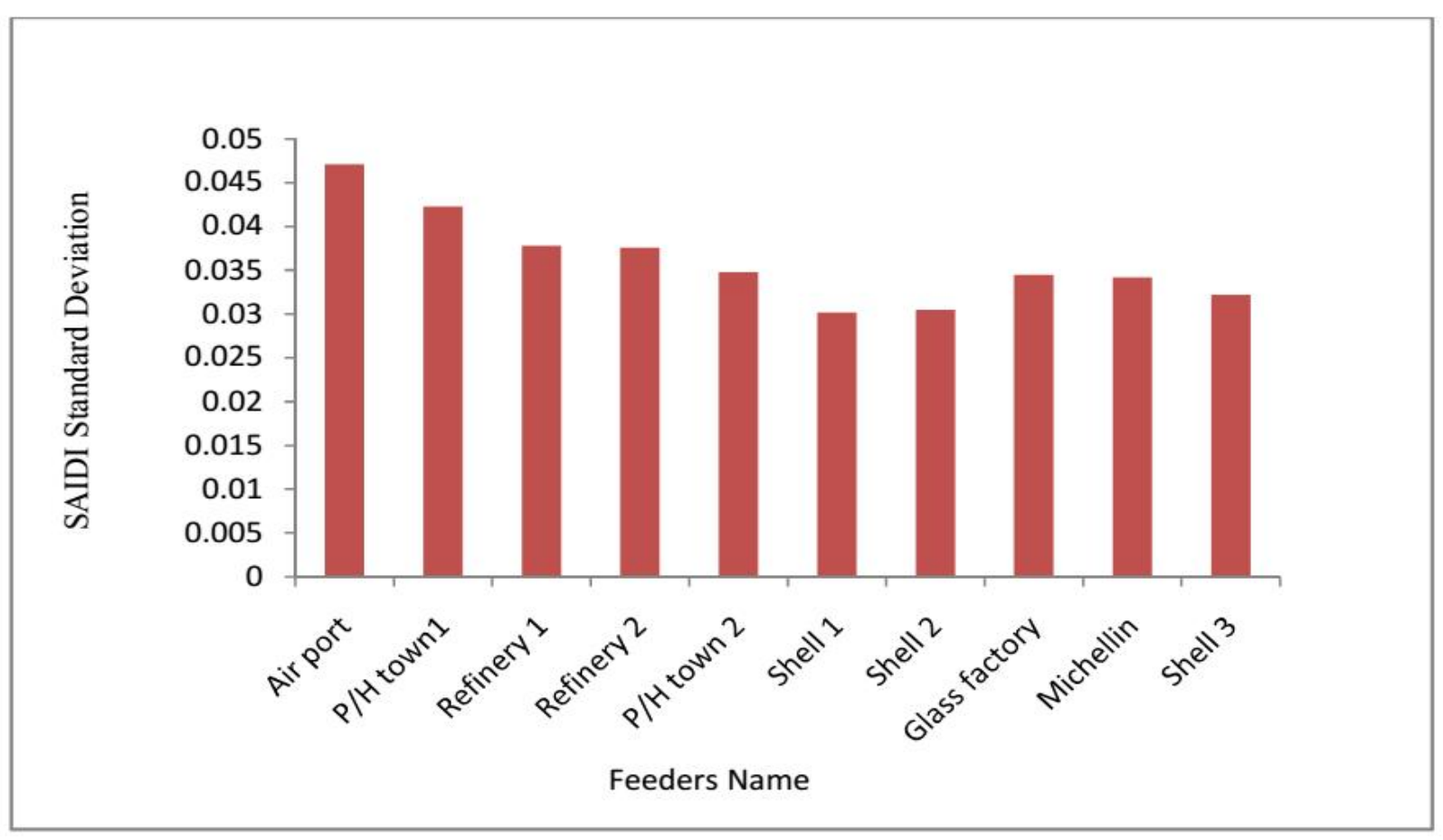

Figure 16: Standard Deviation of SAIDI for Port-Harcourt Distribution Network. 


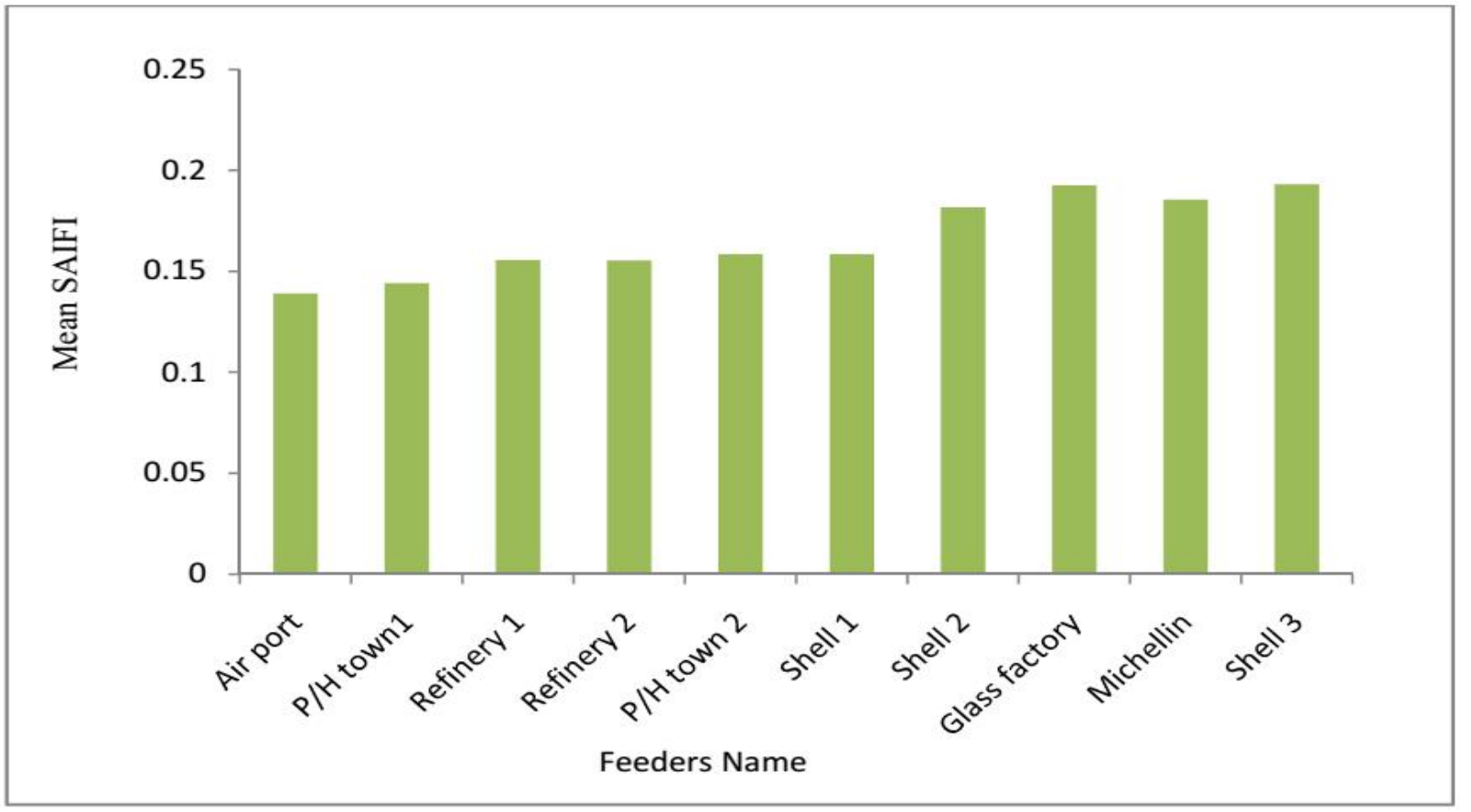

Figure 17: Mean SAIFI for Port-Harcourt Distribution Network.

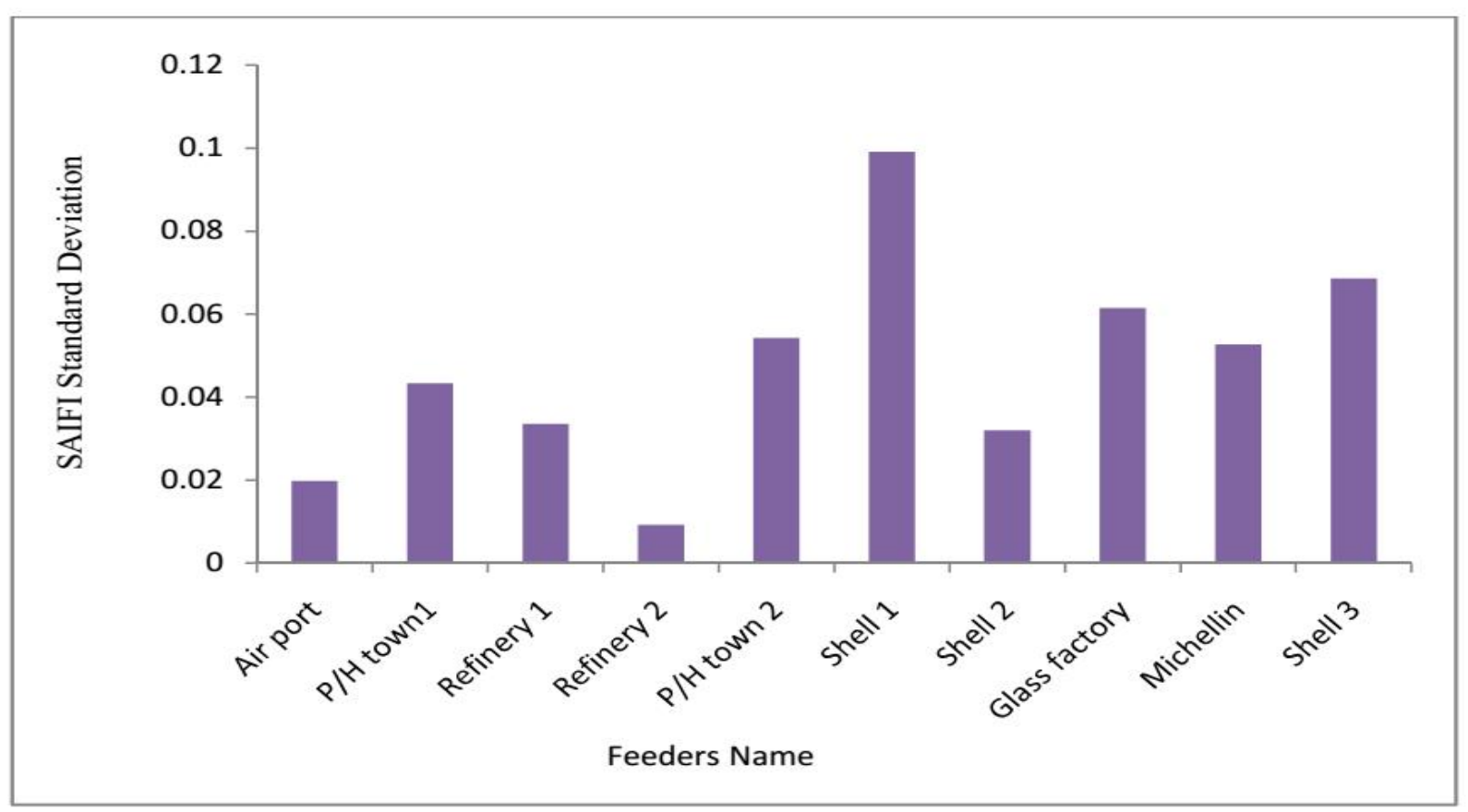

Figure 18: Standard Deviation of SAIFI for Port-Harcourt Distribution Network. 


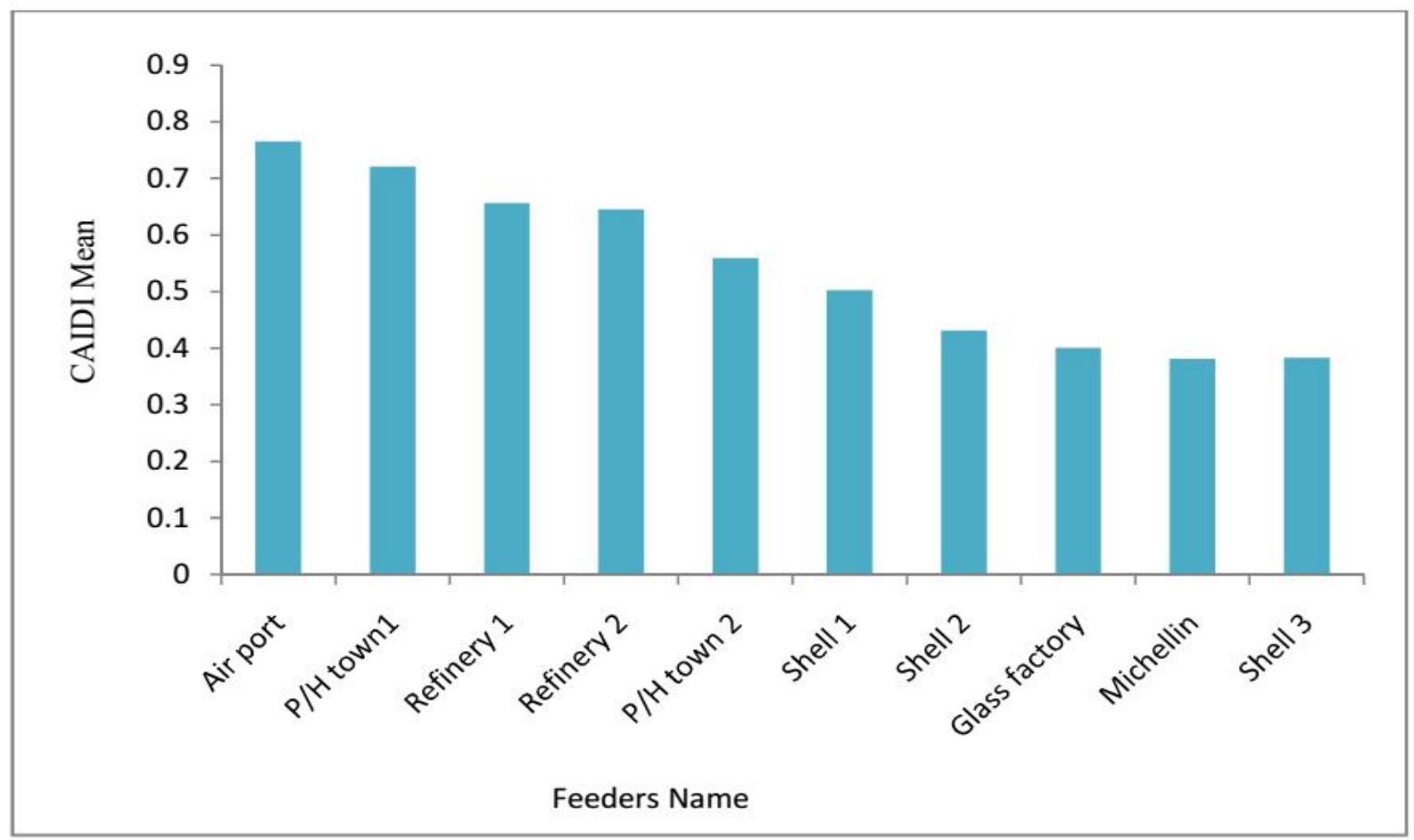

Figure 19: Mean CAIDI for Port-Harcourt Distribution Network.

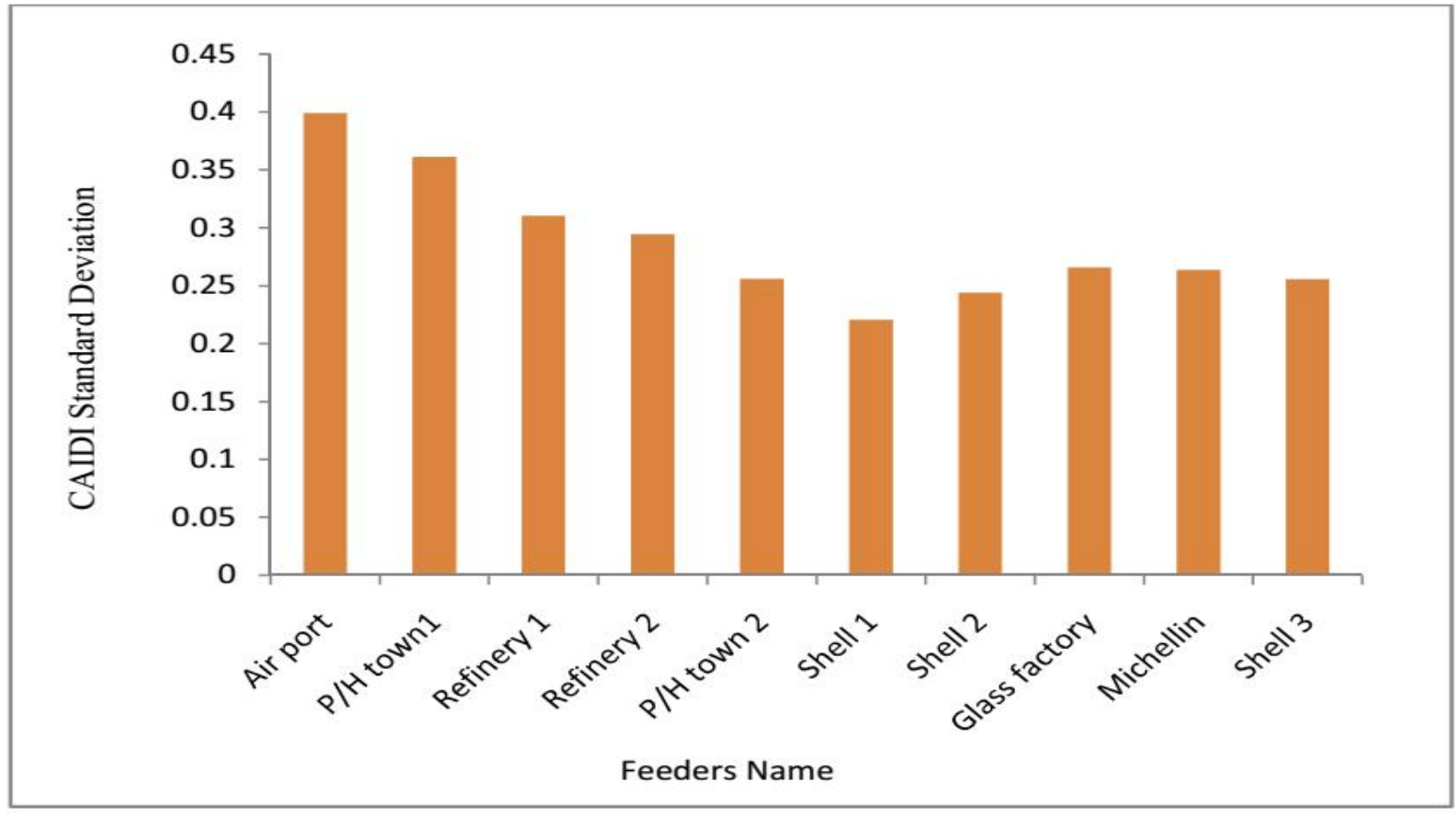

Figure 20: Standard Deviation of CAIDI for Port-Harcourt Distribution Network. 


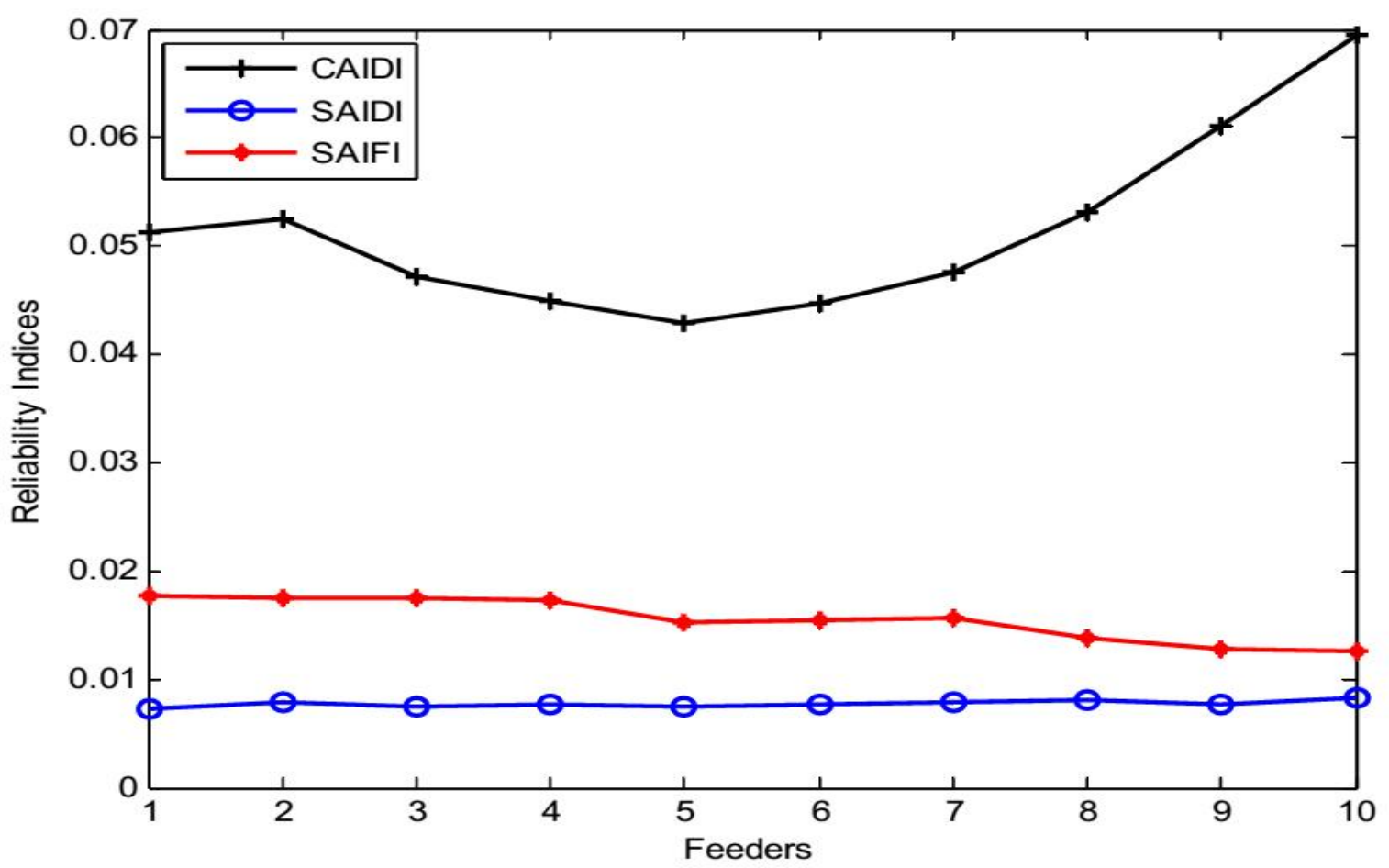

Figure 21: Combined reliability indices for Port-Harcourt Distribution Network.

\section{V.Conclusions.}

This study has analyzed the assessment of system reliability indices of electrical power system of Ibadan, Ikeja and Port-Harcourt distribution network. A Pseudo code was written in MATLAB environment for electrical distribution network reliability analysis with curve fitting tools using ten years of outage data collected from the records of the network operators. Three major system reliability indices-System Average Interruptions Duration Index (SAIDI), System Average Interruptions Frequency Index (SAIFI) and Customer Average Interruptions Duration Index (CAIDI) were identified and computed. The mean and standard deviation of the system reliability indices were computed. Observation shows that the result obtained has demonstrated the applicability of the three system reliability indices on distribution system in terms of technical benefit that compliments the distribution network. Thus these indices improved the reliability levels of the distribution network.

\section{VI.References}

[1] Ajenikoko G.A and Fakolujo O.A. (2012). Reliability indices in the context of the network operator and customer-a review.International Journal of Engineering Innovation, 4(3), 135-138.

[2] Ajenikoko G.A and Fakolujo O.A. (2013). Analysis of faults associated with bare conductors on Ibadan and Ilorin distribution systems", International Journal of Research and Advancement in Engineering Science, 3(1), 114-123.

[3] Ajenikoko G.A and Olaluwoye O.O. (2014). A generalized model for electrical power distribution feeders' contributions to system reliability indices. International Journal of Engineering Research, 3(11), 640-644.

[4] Ajenikoko G.A, Fakolujo O.A and Oyedoja K.O. (2011). A quantitative evaluation of reliability indices for Nigerian national grid: Osogbo transmission system, a case study.African Journal of Engineering Research and Development, 4(1), 150-157.

[5] Ajenikoko G.A, Fakolujo O.A and Raji T.I. (2010). Reliability and quality assurance of electronic component.Journal of Engineering, Science and Technology, 5(2), 51-55.

[6] Aljohani T.M and Beshir M.J. (2017). MATLAB code to assess the reliability of the smart power distribution system using Monte Carlo simulation. Journal of Power and Energy Engineering, 5(3), 30-44.

[7] Allen W.J and Bruce W.F. (2003). Power generation, operation and control. John Wiley and Sons, Inc., 5(2), $204-219$

[8] Balijepalli N. (2002). Advances in distribution system reliability assessment. Retrospective Theses and Dissertations, Iowa State University, 35(7), 1-128.

[9] Barlow R. and Proschan F. (2001). Statistical theory of reliability and life testing probability models. IEEE Transactions on Power Systems, 19(7), 1126-1321.

[10] Buhari M. (2016). Reliability assessment of ageing distribution cable for replacement in smart distribution 
systems. A Thesis submitted to The University of Manchester for the Degree of Doctor of Philosophy in the Faculty of Science and Engineering School of Electrical and Electronic Engineering, Electrical Energy and Power Division, 2(1), 1-191.

[11] Das B and Deka B. (2013). Impact of distributed generation on reliability of distribution system. IOSR Journal of Electrical and Electronics Engineering, 8(1), 42-50.

[12] Feng, Z. (2006), "Electric distribution system risk assessment using actual utility reliability data", Master's Thesis, University of Saskatche wan, 4(7), 14-17.

[13] George, K, Meliopoulos A.P. and George C. J. (2004). Comparison of linearized stochastic power flow and Monte Carlo simulation. presented at the 36th Annual North American Power Symposium (NAPS), Moscow, Idaho. 3(4), 601-615.

[14] Khan E and Billinton R. (2002). A hybrid model for quantifying different operating states of composite power systems. IEEE Transactions on Power Systems, 7(1),93-98.

[15] Kovalev G. F and Lebedeva L. M. (2000). A model for evaluating the reliability of electric power system for long-term operational planning. IEEE Transactions on Power Systems, 7(3), 118-134.

[16] Kowalewski D.A. (2005). A comparable method for benchmarking the reliability performance of electric utilities. Exelon - ComEd., Chicago, IL USA, 2(2), 1-4.

[17] Kundur P. (2004). Power system stability and control. EPRI Power System Engineering Series, MC-Graw Hill. 6(5), 39-58.

[18] Lauby M and Billinton R. (2004): "A probabilistic method for transmission planning" In Proceedings of the 1998 International Conference on Probabilistic Methods Applied to Power Systems (PMAPS), Oakland, California. 7(6), 112-138.

[19] Neto A. C, Da Silva M. G. and Rodrigues A. B. (2006). Impact of distributed generations on reliability evaluation of radial distribution systems under network constraints. 9th International conference on probabilistic methods applied to power systems, KTH, Stockholm, Sweden, 4(5), 716-735.

[20] Okorie P.U and Abdu A.I. (2015). Reliability evaluation of power distribution network system in Kano metropolis of Nigeria. International Journal of Electrical and Electronic Science, 2(1), 1-5.

[21] Sacket R. K, Bansal R. C and Singh C. O. (2007). Reliability evaluation of power system considering voltage stability and continuation power flow on power system. IEEE Transactions on Power Systems, 7(1), $258-263$.

[22] Sindi H and El-Saadany E. (2016). Unified reliability index development for utility performance assessment developing a novel normalization-based index and comparing it with a fuzzy inference unified index. Intell Journal of Industrial System, 2(3), 149-161.

[23] Sun W.K and Meliopoulos A.P. (2002). Contingency selection via quadratized power flow sensitivity analysis. In Proceedings of the IEEE 2000 Power Engineering Society Summer Meeting, 3(8), 1494-1499.

[24] Xiu-Ren L, Zhen R, Wen-Ying H and Bi-Yun C. (2005). Fussy reliability analysis of distribution systems accounting parameters uncertainty. In proceedings of the fourth international conference on machine learning cybernetics. 5(6), 90-109.

[25] Xu L, Chow M and Taylor S. (2001). Analysis of tree caused faults in power distribution systems. IEEE Transactions on power systems, 23(6), 321-33. 